\title{
Concise Estimation for Detection of Coronavirus COVID19
}

\author{
EM Ahmed ${ }^{* 1}$ and Marwa Al Moghazy \\ ${ }^{1}$ Department of Microbial products, Egypt \\ ${ }^{2}$ Department of Dairy Science, National Research center, Egypt \\ *Corresponding author: EM Ahmed, Department of Microbial products, Egypt
}

\section{ARTICLE INFO}

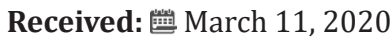

Published: March 19, 2020

Citation: EM Ahmed, Marwa Al Moghazy. Concise Estimation for Detection of Coronavirus COVID19. Biomed J Sci \& Tech Res 26(4)-2020. BJSTR. MS.ID.004392.
Abstract

The panic from the outbreak of the new coronavirus make the rapid and accurate detection of the virus a crucial issue. The growing increase in number of the infected people forced a global desire toward the rapid detection. The accurate detection can participate in saving the life of many people. The number of people with novel coronavirus disease 2019 (COVID-19) has risen above 75000 globally, over 99\% of whom are in China, with more than 900 cases in 25 other countries as of Feb 20, 2020. Science, however, is stepping up to the challenge. Consider the example of Africa's efforts to scale up its capacity to detect any cases of infection [1,2].

\section{Short Communication}

\section{Serology Rapid Tests}

The common IgG/IgM test depend on antibodies detection. It is difficult to say that the rapid tests are accurate because COVID 19 share laboratory features with other viruses. So, the false positive results are expected to certain extent [3]. This represents a problem not only to the patients but also to the public health. However, the test is suitable for screening purposes in large gathering.

The Molecular Methods

\section{PCR Amplification Technique}

RT-PCR (Reverse Transcriptase PCR): RT-PCR is the golden test for the most laboratory diagnosis purposes. PCR depends on amplification of the DNA strand using polymerase enzyme. Since this test can amplify the small quantity of Nucleic acid it is considered the test of the high accuracy and high sensitivity for detection of the viral infection $[4,5]$.

Real time RT-PCR: Real-time reverse transcriptase-PCR (RTPCR) detection now is common for the detection of coronavirus because of its high specificity, simplicity and quantitative assay. Re al-time RT-PCR is more sensitive than the conventional than RT-PCR assay, and this show more help in the diagnose in early stages of the viral infection $[6,7]$. For these reasons a real time RT-PCR assay is a predominant method to be applied for the detection of all kinds of coronaviruses $[8,9]$. In spite of this advantages the real time is time consuming because of the need for careful handling and the chance of contamination. Another problem is the rapid mutating nature of the coronavirus . Utilization of the multiplex Real time PCR mad reduce the ration of false negative during detection of the new corona virus. Hadjinicolaou, et al. [10] develop a real time PCR test depending on detection of four genes and use an internal control and this can reduce the false negative problem.

\section{Other Nucleic Acid Amplification Techniques}

Isothermic Amplification Methods: LAMP test is isothermal amplification technic uses single tube for amplification of DNAs and RNAs. The test has high sensitivity and high specificity because of the exponential amplification feature and 6 different sequences can be identified by 4 different primers simultaneously, respectively [11]. Lower cost than PCR tests and rapidity of the test may make it as a good choise for detection coronavirus [12].

Rolling Circle Amplification-Based Methods: Anther isothermal amplification method is( RVA) . This is a time saving meth- 
od able to detect the target nucleic acid. The RCA is able to amplify the nucleic acid 109 -fold signal amplification of each circle within $90 \mathrm{~min}$. It is an efficient test for detection of SARS-CoV . Only few reagents is required for carrying up RCA and false positive is rare in contrast to PCR method [13,14]. For RCA an antibody coated microplate as a signal enhancement strategy is an excellent biosensing platform. That cleverly avoided the using of complex instruments and offered a visual detection of the molecular binding events under an ordinary experiment conditions [15].

Microarray Based Methods: The microarray is a rapid and efficient method. cDNA labeled id produced from the RNA templet of the virus through reverse transcription. Then these labeled cDNAs will be loaded into each well and hybridize with solid phase oligonucleotides fixed on the microarray followed by a series of washing steps to remove free DNAs. Finally, the coronavirus RNA can be detected by the detection of specific probes. Due to its efficiency, the microarray assay is widely used for detection of coronavirus. Microarray requires instrument of high cost a [16].

\section{References}

1. WHO (2020) Coronavirus disease (COVID-2019) situation report.

2. WHO (2020) WHO Director-General's opening remarks at the mission briefing on COVID-19.

3. Chen N, Zhou M, Dong X, Qu J, Gong F, et al. (2020) Epidemiological and clinical characteristics of 99 cases of 2019 novel coronavirus pneumonia in Wuhan, China: A descriptive study. Lancet 395: 507-513.

4. D Adachi, G Johnson, R Draker, M Ayers, T Mazzulli, et al. (2004) Comprehensive detection and identification of human coronaviruses, including the SARS-associated coronavirus, with a single RT-PCR assay. J Virol Methods 122(1): 29-36.

5. TY Setianingsih, A Wiyatno, TS Hartono, Evi Hindawati, Rosamarlina, et al. (2019) Detection of multiple viral sequences in the respiratory tract samples of suspected Middle East respiratory syndrome coronavirus patients in Jakarta, Indonesia 2015-2016. Int J Infect Dis 86: 102-107.
6. ZZ Wan, YN Zhang, ZX He, Jia Liu, Ke Lan, et al. (2016) A melting curvebased multiplex RT-qPCR assay for simultaneous detection of four human coronaviruses. Int J Mol Sci 17(11).

7. JY Noh, SW Yoon, DJ Kim, MS Lee, JH Kim, et al. (2017) Simultaneous detection of severe acute respiratory syndrome, Middle East respiratory syndrome, and related bat coronaviruses by real-time reverse transcription PCR. Arch Virol 162(6): 1617-1623.

8. VM Corman, I Eckerle, T Bleicker, A Zaki, O Landt, et al. (2012) Detection of a novel human coronavirus by real-time reverse-transcription polymerase chain reaction. Euro surveillance 17(39): 3-8.

9. XY Lu, B Whitaker, SKK Sakthivel, S Kamili, LE Rose, et al. (2014) Realtime reverse transcription-PCR assay panel for Middle East respiratory syndrome coronavirus. J Clin Microbiol 52(1): 67-75.

10. AV Hadjinicolaou, GA Farcas, VL Demetriou, T Mazzulli, SM Poutanen, et al. (2011) Development of a molecular-beacon-based multi-allelic real-time RT-PCR assay for the detection of human coronavirus causing severe acute respiratory syndrome (SARS-CoV): A general methodology for detecting rapidly mutating viruses. Arch Virol 156: 671-680.

11. T Notomi, H Okayama, H Masubuchi, T Yonekawa, K Watanabe, et al. (2000) Loop-mediated isothermal amplification of DNA. Nucleic Acids Res 28(12): E63.

12. M Enosawa, S Kageyama, K Sawai, $\mathrm{K}$ Watanabe, $\mathrm{T}$ Notomi, et al. (2003) Use of loop-mediated isothermal amplification of the IS900 sequence for rapid detection of cultured Mycobacterium avium subsp. Paratuberculosis. J Clin Microbiol 41(9): 4359-4365.

13. MC Xu, JW Ye, D Yang, AAA Al Maskri, H Hu, et al. (2019) Ultrasensitive detection of miRNA via one-step rolling circlequantitative PCR (RCqPCR). Anal Chim Acta 1077: 208-215.

14. WK Wang, CT Fang, HL Chen, CF Yang, YC Chen, et al. (2005) Detection of severe acute respiratory syndrome coronavirus RNA in plasma during the course of infection. J Clin Microbiol 43(2): 962-965.

15. Lide Gu, Wanli Yan, Le Liu, Shujun Wang, Xu Zhang, et al. (2018) Research Progress on Rolling Circle Amplification (RCA)-Based Biomedical Sensing. Pharmaceuticals (Basel) 11(2).

16. Q Chen, J Li, ZR Deng, W Xiong, Q Wang, et al. (2010) Comprehensive detection and identification of seven animal coronaviruses and human respiratory coronavirus 229E with a microarray hybridization assay. Intervirology 53(2): 95-104.
ISSN: 2574-1241

DOI: $10.26717 /$ BJSTR.2020.26.004392

EM Ahmed. Biomed J Sci \& Tech Res

(C) (P) This work is licensed under Creative

Submission Link: https://biomedres.us/submit-manuscript.php

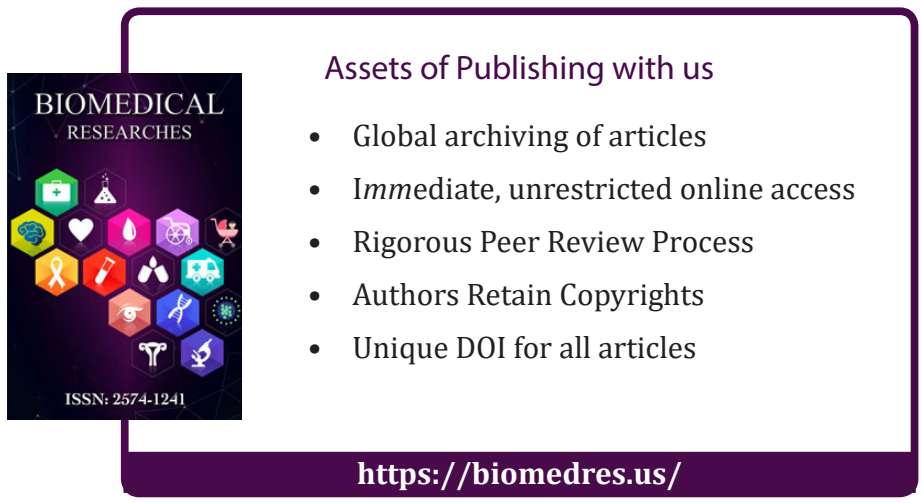

